\title{
علامة نائب الفاعل في القرآن الكريم في جزء 30 و تحليلها
}

\author{
Muhammad Jabir, Masyitah Nur Rahmi \\ Institut Agama Islam Negeri Palu, Indonesia \\ Jl. Diponegoro No. 23, Kec: Palu Barat, Kota Palu, Sulawesi Tengah, 94221, Indonesia
}

Corresponding E-mail: mjabir@gmail.com

\begin{abstract}
This thesis is a literature study, and the objectives of this study are: to find out the types of subject replacement in chapter 30, and to find out the cause of the deletion of the subject. The method used in this scientific research is desk research. The method of data collection in this research is the method of identifying the verses of the Qur'an that have a substitute subject in it, which is contained in chapter 30, and then analyzing the substitute for the subject in the participle. using grammar rules related to subject substitution, commentaries and books related to subject participles. The results of the analysis show that there are 63 substitute subjects in chapter 30. It is divided into 4 parts. First substitute the obvious subject; second, substitute subject in the form of isim dhamir; third, substitute for the subject in the form of number; fourth, substitute for the subject in the form of isim maushul. And also found the cause of the aborted subject, namely because it is common place; and ignorance of the subject.
\end{abstract}

Keywords: Naib al Fa'il, alquran.

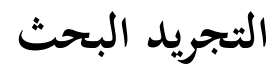

$$
\begin{aligned}
& \text { هذه الرسالة هو البحث المكتبي , أما الأهداف من هذا البحث هي: لمعرفة أنواع نائب الفاعل } \\
& \text { في جزء 30، ولمعرفة أسباب حذف الفاعل حتى يكون له نائب في تلك السور.واما المنهج الذي } \\
& \text { ييسنخدم في هذا البحث العلمي هو البحث المكتبي. وأما أساليب همع البيانات في هذا البحث هو } \\
& \text { طريقة تحديد الآيات القرآنية التي تتضمن نائب الفاعل في القرآن الكريم يعني في جزء } 30 \text { ثم تحليل } \\
& \text { أسباب حذف الفاعل في نائب الفاعل باستخدام قواعد النحو عن نائب الفاعل والتفاسير والكتب } \\
& \text { التي تتعلق بنائب الفاعل. ونتائج في هذا البحث توجد ثلاث و ستّين نائب الفاعل في جزء 30، من } \\
& \text { أربع أنواع و هي نائب الفاعل الصارح (27) و نائب الفاعل المضمر (33) و نائب الفاعل الجملة } \\
& \text { (1) و نائب الفاعل اسم الموصول (2). وتوجد أيضا أسباب حذف الفاعل في نائب الفاعل من تلك } \\
& \text { السور،و هي للعلم به (53) و للرغبة في إخفائه للإبهام (9) للجهل به (1). }
\end{aligned}
$$


كانت من جهة المفردات أو الأصوات أو

الأشكال أو التراكيب أو من جهة المعاني.

اللغة العربية هي لغة العلم والمعرفة

ووسيلة الاتصال بين الناس في النشاطات اليومية

سواء كان بين شخص و شخص آخر أم بين

شخص وبجتمعه، يعني أن اللغة العربية من

إحدى الوسائل لتبليغ الفكر أو الرأي أو

الشعور

فاللّغة العربيّة خاصّة سهم مهم في الحياة

لأهما لغة القرآن الكريم والأحاديث الشّرفية كما

قال الشّيخ مصطفى الغلاييني بقوله "اللّغة

العربيّة هي الكلمات التي يعبّر بها العرب عن

أغراضهم. وقد وصلت إلينا من طريق النّل. و و

حفظها لنا القرآن الكريم و الأحاديث الشرفية،

و ما رواه الثّقات من منثور العرب و و

منظومهم".

ومن جهة التراكيب، استغنت اللّغة

العربيّة بالقواعد النحويّة التي هي عاملة لتعيين

مقام الكلمة في الجملة كما قال السيّد أحمد

الهاشمي في كتابه "القواعد الأساسيّة للّغة العربيّة"

$$
\text { 3. القرآن، } 12 \text { (يوسف) } 2 .
$$

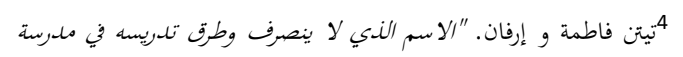

الخيرات العالية بالو"، البارق 1، رقم. 1 (2020)

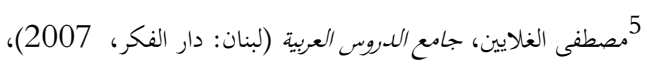

يؤمن المسلمون بأن القرآن هو كتاب الله

الذي أنزله إلى النبي محمد بن عبد الله صلّى الله عليه و سلم. و القرآن هو كلام الله المعجز، المنزّل على خاتم الأنبياء و المرسلين رسولنا محمد صلّى الله عليه و سلّم بواسطة الأمين جبريل عليه السّلام، المكتوب في المصاحف، المنقول إلينا بالتواتر، المبدوء بسورة الفاتحة و المختتم بسورة الناس.

قد أُنزل القرآن هدًى للنّاس و بيّنات من الهدى و الفرقان، و لمُ يجعل له عواجُا. فيه علوم كثيرة و متنوّعة و منتفعة لقوم يعقلون. فيه المبادئ الأساسيّة و القيم العلميّة الّتي شملت جميع جوانب الحياة البشرية.

من المعلوم أن القرآن قد أنزل إلى نبينا

محمد صلى الله عليه وسلم باللغة العربيّة. قال

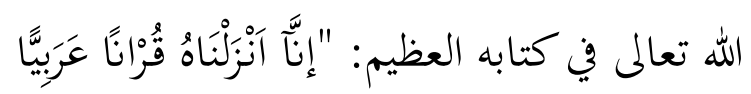

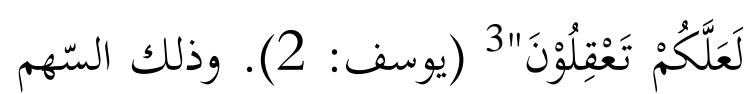
يطلب إلينا لفهم العناصر في اللّغة العربيّة سواء محمّد علي الصابوني، التبيان في علوم القرآن (ط.

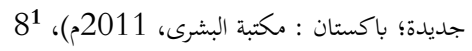

${ }^{2}$ M. Asy'ari, Metodologi Pendidikan dan Pengajaran Perspektif Al-Qur'an dan Hadits (Tangerang : Rabbani Press, 2017), 3 
يكون" عمدة بعد أن كان فضلة فلا يجوز حذفه ولا تقدميه على الفعل و يجب تأنيث الفعل إن

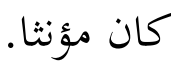

اختارت الباحثة الموضوع في هذا البحث

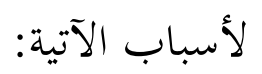

1. احظت الباحثة أنه في كلية

التربية و علوم التدريس بقسم تعليم اللغة العربية بالجامعة الإسلامية الحكومية بالو، لم يكن هناك الموضوع في رسالة الذي نشأ عنه نائب الفاعل. 2. ت تختار الباحثة جزء الثلاثين

من القرآن الكريم ، لأن لديها كثير من السور في القرآن الكريم وهم Vr سور. مجموعة السور التي حفظها أكثر الناس في صلواتم وأذكارهم . فيه فوائد العظيمة والحكم الكثيرة وفيه أيضا الدور الأساسي لبناء العقائد وأجيال موالاة

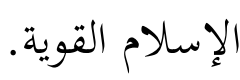

بالنظر إلى تصوير المذكور السابق، فتشعر الباحثة باهتمام لبحث وعلم عن نائب الفاعل و أسباب حذف الفاعل فيه في القرآن 8إعبد الله ابن الفاضل الشيخ العشماوي، شرح حاشية لعشموي (سورابايا: الهداية، دون سنة)، 25 9محمد بن محمد الرعيني، متممة الأجرومية الطبعة الرابعة الجزء الأول دلول

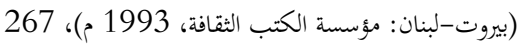

أنّ النّحو في اصطلاح العلماء هو قواعد يعرف هما أحوال أواخر الكلمات العربيّة التّي حصلت بتركيب بعضها مع بعض من إعراب و بناء وما يتبعهما. ' ويرى فؤاد نعمة أنّ النّحو هو قواعد يعرف هما وظفية كل كلمة داخل الجملة، وضبط أواخر الكلمات، وكفيية إعرابها7 في علم النحو أما مرفوعات الأسماء سبعة وهي الفاعل والمفعول الذي لم يسم فاعله (نائب الفاعل) والمبتدأ وخبر المبتدأ واسم كان وأخواهما والتابع للمرفوع وهو أربعة أشياء النعت والعطف والتوكيد والبدل 8

وفي القرآن الكريم كثير من مرفوعات الأسماء منها نائب الفاعل الذي سيبحث في هذا البحث. نائب الفاعل هو الاسم المرفوع الذي لم يذكر معه فاعله. 9 وله أيضا بجوث واسعة لا سيما بالنظر إلى التغيير في أصل الكلمة أن لما فاعل حتى ليس لها فاعل بل نائب الفاعل. ومن خصائصه أن يكون له حكم رفع بعد نصب لأن الأصل أنه مفعول به. ومنها أن 
مثل : هُزَِْ العَدُوُ (العدوُ : نَائبِ الفاعل

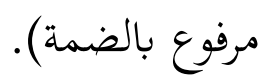

و تتغير صورة الفعل عند بنائه للمجهول

أ) الفعل الماضي : ضُمَّ أَوَلُهُ وكثر ما قبل آخره مثلا صَنع التجار الأثاثُ : صُنع

الأثاثَ

واذا كان الفعل مبدوءا بالتاء، صمّ ثانية مع

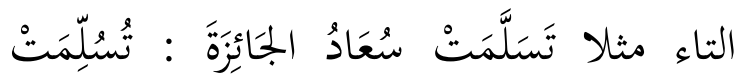
الجَائزةٌة

واذا كان ماقبل آخره ألفا قلبت ياء وكسر

ما قبلها مثلا قَالَ الشَاهِدُ الحقُّ : قِيْلَ الحَقُّ ب) الفعل المضارع : ضمّ أوله وفتح ما قبل آخره مثثلا يسُرُ الَزْهرُ العينين : تُسرَُُ العَيْنَانِ

وإذا كان ماقبل آخره ياء أو واوأ قلبت ألفا

مثلا يَبِيْعُ الفلاحُ القُطنَ : يُبَاعُ القُطْنُ 13

\section{أسباب حذف الفاعل}

أ) اما للعلم به، فلا حاجة إلى ذكره، لأنه معروف نحو: (و خُلقََ الإنْسَانُ ضَعْيْفًا)

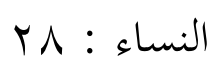

الكريم عميقا وتكتبها في البحث العلمي تحت العنوان: "نائب الفاعل في القرآن الكريم في جزء

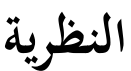

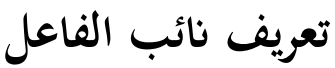

نائب الفاعل هو اسم مرفوع يقع بعد

فعل مبني للمجهول ويحل محل الفاعل بعد حذفه

أو المسند إليه بعد الفعل المجهول أو شبهه و ولهي حذف الفاعل يكون إما للعلم به أو الجهل به، أو الخوف منه أو عليه. 10

و نائب الفاعل هو المسند إليه بعد

الفعل المجهول أو شبه. 11 و تفسر أيضا على له أها اسم مرفوع تقدمه فعل تام تصرف مبني للمجهول أو شبهه، وحلّ محلّ الفاعل بعد حذفه. 12 نحو (يُكرُمُ المجتهُُُ والمحمودُ حُلقُهُ،

فا المجتهد أسند إلى الفعل البمهول، وهو : (يُكرَمُ) وخلقه أسند إلى شبه الفعل المجهول،

وهو (الممود).

$$
13 \text { أحمد الهاشمي، القواعد، } 92 \text { نفس المراجع.، } 85
$$

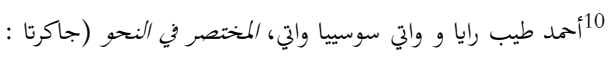

$$
\begin{aligned}
& \text { الجامعة شريف هداية الله الإسلامية الحكومية، 2016)، } 83 \\
& 11
\end{aligned}
$$


أ) المفعول به, وهو الأصل المقدم على غيره في النيابة عن الفاعل، وهو : إمّا أن يكون واحدا، وإمّا أن يكون متعددا فإن كان المفعول به واحدا، أقيم هو نائبا عن الفاعل، نهو : قُضِيَ الأَمْرُ وَ إِنْ كَانَ متعلِّدًا، أنيب الأوّل وبقي ما يليه منصوبا على حاله، نخو : أُعطيَ المخترعُ مكافأةًة ووجد الخبر صحيحا، وأعلم المستفهم الأمر واقعا، وأخبر الأمير الأمن سائدا، ووجد

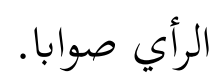

ب) المصدر, ينوب عن الفاعل بعد حذفه بشرط أن يكون متصرّفا مختصّا يصحّ الإسناد إليه، نحو : كُتِبَتْت كِتَابَةُّ حَسَنَةُ. فلا ينوب المصدر الملازم النّصب، نهو : مَعاذَ، وسُبحَانَ. و لا المبهم لعدم الفائدة، كسير، فيمتنع : يُسارُ سَيرِّ. ج) الظرف, ينوب عن الفاعل بعد حذفه بشرط أن يكون متصرّفا مختصا، كالمصدر، نهو صيم رمضان، وسهرت الليلة. فلا ينوب، نحو معَكَك، وعِندَكَ؛ لأغما لا لا يفارقان النّصب ولا نحو : زمان، و مكان؛ لعدم الفَائيَدة.
ب) و واما للجهل به، فلا يمكنك تعينه، نهو: لاسُرِقَ البَّيتُ 《، إذا لم تعريف السارق. ت) و إما للرغبة في إخفائه لأهمام، نحو: رُركبَ الحِصَان، إذا عرفت الراكب غير أنك لمُ ترد إظهاره. ث) و إما للخوف عليه نحو : 》ضُربَب فَلَانه إذا عرفت الضارب غير أنك خفت عليه، فلم تذكره. ج) و إما للخوف منه، نخو : السرق الحصانه إذا عرفت السارق فلم تذكره،

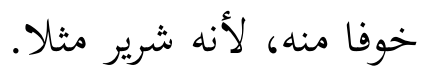
ح) و إما لشرفه، نحو : لاعُمِلَ عَمَلٌْ مِنْكَرُه، إذا عرفت العامل فلم تذكره، حفظا لشرفه. خ) و إما لأنه لا يتعلق بذكره فائدة، نهو :

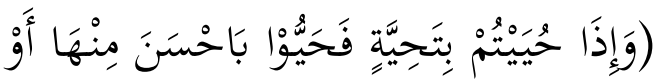
رُردُّهَا) النساء : 86، فذكر الذي يهيّي لا فائدة منه، وإنما الغرض وجوب ردّ التحية وبتري جميع أحكام الفاعل والفعل المعلوم على نائب الفاعل، والفعل المجهول وتسمّى الجملة المرّكبة من الفعل وفاعله، أو نائب فاعله (جملة فعلية). 14 الأشياء التي تنوب الفاعل 14 أممد الهاشي، القواعد، 93 
مصدر مؤول من (أن والفعل، أو أنّ واسمها و خبرها). مثل : عُرِفَ أنكُ كرَك

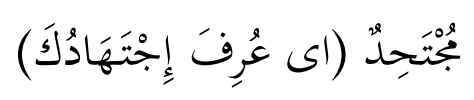

مصدر صريح أو ظرف متصرف أو جار

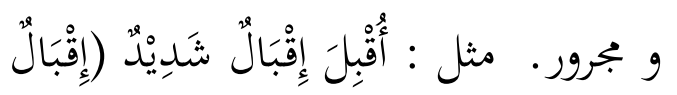

: مصدر وهو نائب الفاعل) لاَيُسْكِتُ

عَلَى إِهَانَةِ (عَلَى إِهَانَةِ : جار ومجرور نائب

$$
\text { فاعل) }
$$

أحكام نائب الفاعل

كل ما تقدم من أحكام الفاعل يجب أن يراعى مع نائبه، لأنّه قائم مقامه، فله حكمه:

$$
\text { أ) أ فيجب رفعه }
$$

ب) وأن يكون بعد المسند ج) وأن يذكر في الكلام

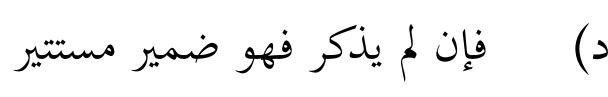

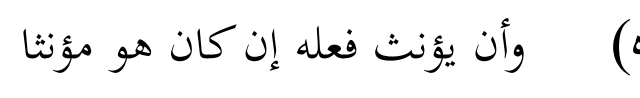

و) وأن يكون فعله موحّدا، وإن كان هو

مثنّى أو مجموعا. ويجوز حذف فعله

لقرينه دالة عليه 17
د) جار مع مجرور : ينوب عن الفاعل بعد حذفه بشرط أن يكون مختصّا بإضافة، أو صفة، نهو : نُظِرَ في حَاجتِكَ ونحو : تُكُلِّمَ في أَمر هَامِّ لك اليوَ وإذا كان المجرور مؤنثا فلا تلحق فعله علامة التأنيث، فتقول : مُرَّ كهندِ لا مرّت لأنه لم يسند إليه صريحا. ويجوز تقديم المجرور على فعله باقيا على نيابته له،

$$
\text { فتقول : إبهندِ مُرَّرَ } 15
$$

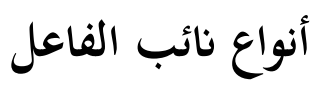

$$
\text { نائب الفاعل أربعة أنواع : }
$$

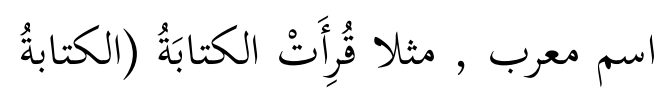

: نائب الفاعل مرفوع بالضمة) يُخْرَمُ

المجَاهدُ (المجاهدُ : نائب الفاعل مرفوع

بالضمة)

(2

ب) اسم مبني (ضمير ظاهر او مستتر، اسم إشارة، اسم موصول). مثل : فَوُجِيْتُ بِِيَرَتِكَ (التاء ضمير ظاهر مبني في محل

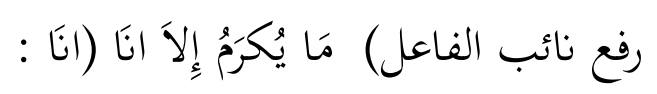

ضمير منفصل مبني في محل رفع نائب

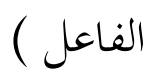


سُورَةُ النَّازِعَاتِ، وهي مكية. 21 وآيها:

ست وأربعون آية، وحروفها: سبع مئة وثلاثة

وسبعون حرفًا، وكلمها: مئة وتسع وسبعون

$$
\text { كلمة. } 22
$$

$$
\text { محة عن سورة عبس }
$$

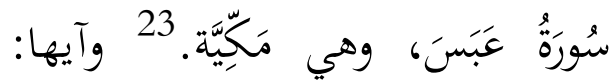

أربعون وآيتان (1)، وحروفها: خمس مئة وستة

وثلاثون حرفًا، وكلمها: مئة وثلاث وثلاثون

$$
\text { كلمة. }
$$

لمحة عن سورة التكوير

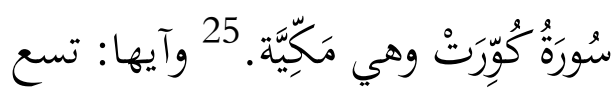

وعشرون آية، وحروفها: أربع مئة وخمسة

وعشرون حرفًا، وكلمها: مئة وأربع كلمات. 26

لمحة عن سورة الانفطار

سُورَةُ الانْفِطَارِ، وهي مَكِّيَّة. 27 وآيها:

تسع عشرة آية، وحروفها ثلاث مئة وسبعة وعشرون حرفًا، وكلمها: إحدى وتمانون كلمة. 28

لمحة عن سورة المطففين
لمحة عن سور في جزء 30

لمحة عن سورة النبأ سُورَةُ النَّبَاِ، وهي مَكِكِيَّة. 18 ليس فيها نسخ ولا حكم، وآيها: أربعون آية، وحروفها: سبع مئة وسبعون حرفًا، وكلمها: مئة وثلاث وسبعون كلمة. 19 إثبات البعث وتعداد النعم الإلهية. لا تكاد بتحد سورة مكية (أي نزلت في مكة قبل الهجرة) إلا وفيها حديث عن البعث، إما بالإثبات وغرس اليقين حوله، بالقسم أو بإيراد أدلة عقلية وحسية على إمكانه، وإما بوصف أهواله ومخاوفه وآثاره الخطيرة التي تنحصر في شيئين: دخول الجنان أو الزج بالنيران، لأن التشريع المكي عني غالبا بالعقائد، وأهمها توحيد الله ونبذ الشرك، وإثبات النبوة أو الرسالة والوحي، ووقوع القيامة، ووصف القيامة رهيب كما في مطلع سورة النبأ المكية اتفاقا. 20 لمحة عن سورة النازعات

$$
\begin{aligned}
& 22 \text { بجير الدين، فتح، } 583 \\
& 23 \text { محمد، تفسير، } 585 \\
& \text { 24 } \\
& \text { 25 25مد، تنسير، الدين، نعاح، } 586 \\
& \text { 26 26جير الدين، فتح، } 586
\end{aligned}
$$

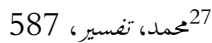

$$
\begin{aligned}
& \text { 28 } 587 \text { الدين، فتح، تغدي، } 587
\end{aligned}
$$

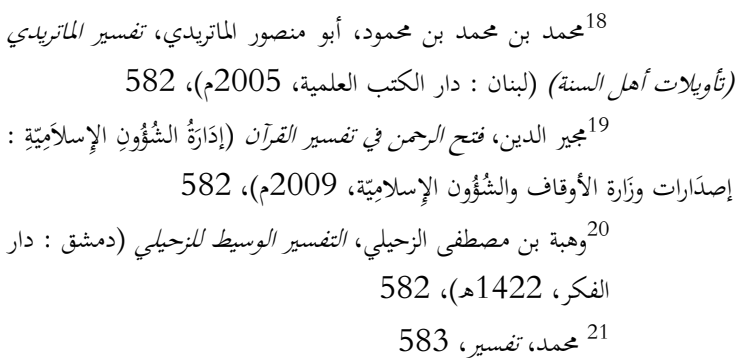


لمحة عن سورة الغاشية

سُورَةُ الغَاشِيَة مكية، و وآيها:

ست وعشرون آية، وحروفها: ثلاث مئة وأحد وسبعون حفًا، وكلمها: اثنتان وتسعون

$$
\text { كلمة. }
$$

$$
\text { لمحة عن الفجر }
$$

سُورَةُ الفَجْر مكية على الأصح، وآيها:

ثلاثون آية، وحروفها: خمس مئة وسبعة وستون

حرفًا، وكلمها: مئة وسبع وثلاثون كلمة. 37

$$
\text { لمحة عن سورة الليل }
$$

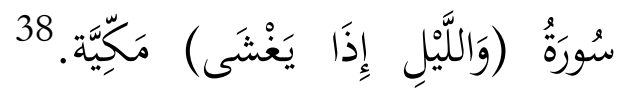

وقيل: مدنية، وقيل: فيها مدلي، وآيها: إحدى

وعشرون آية، وحروفها: ثلاث مئة حرف،

وكلمها: إحدى وسبعون كلمة. 39

$$
\text { لمحة عن سورة البينة }
$$

سُورَةُ الْبَينَةَة، وهي مدنية. 40 مككية على

الأشهر، وقيل: مدنية، وآيها: ثماني آيات،

وحروفها: أربع مئة وثلاثة أحرف، وكلمها: أربع

$$
\text { وتسعون كلمة. } 41
$$

سُورَةُ الْهُطَفِفِينَ، وهي مَكِيَّة. 29 مدنية، وقيل: مكية، وعن ابن عباس: نزل بعضها بمكة، ونزل أمر التطفيف بالمدينة؛ لأفم كانوا أشدَّ الناس فسادًا، أي: في بهذا المعنى، فأصلحهم الله بهذه السورة (1)، وآيها: ست وثلاثون آية، وحروفها: سبع مئة وأربعون حرفًا، وكلمها: مئة وتسع وستون كلمة. 30 عنة سورة الانشقاق سُورةٌ الانشِقَاقِ مكية، و وآيها: خس وعشرون آية، وحروفها: أربع مئة وستة وثلاثون حرفًا، وكلمها: مئة وسبع كلمات. 31 لمحة عن سورة البروج

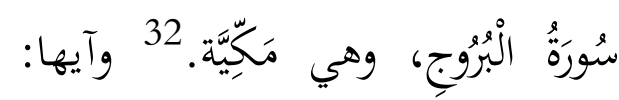
اثنتان وعشرون آية، وحروفها: أربع مئة وأربع وستون حرفًا، وكلمها: مئة وتسع كلمات. 33 لمة عن سورة الطارق سُورَةُ الطَاِِقِ، وهي وآيها: سبع عشرة آية، وحروفها مئتان وتمانية وأربعون حرفًا، وكلمها: إحدى وستون كلمة. 35

$$
\begin{aligned}
& \text { 35 } 591 \text { بحير الدين، فتح، } \\
& \text { 36بير الدين، فتح، } 592 \\
& 593 \text { 37 } 593
\end{aligned}
$$

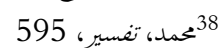

$$
\begin{aligned}
& \text { 393ير الدين، فتح، نغتر، } 595 \\
& \text { 40 }
\end{aligned}
$$

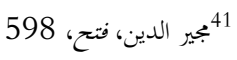

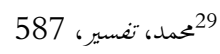

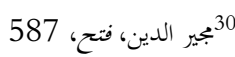

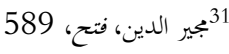

$$
\begin{aligned}
& \text { 32 } 3000 \text { كمد، تفسير، } 590 \\
& 590 \text { 33 }
\end{aligned}
$$

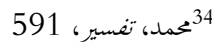


مختلف فيها، وآيها: أربع آيات،

وحروفها: سبعة وأربعون حرفًا، وكلمها: خمس عشرة كلمة.

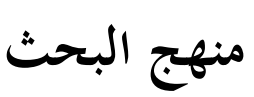

منهج هذا البحث العلمي هو البحث المكتبي. أما أساليب جمع البيانات في هذا البحث هو طريقة تحديد الآيات القرآنية التي تتضمن نائب الفاعل في القرآن الكريم يعني في جزء 30 ثم تحليل أسباب حذف الفاعل في نائب الفاعل باستخدام قواعد النحو عن نائب الفاعل والتفاسير والكتب التي تتعلق بنائب الفاعل. وأما أساليب تحليل البيانات في هذا البحث هو تحليل التفسريي بالرجوع إلى التفسري التي قدمه المفسرون في كتبهم، تحليل النحو بالرجوع إلى تلى الكتب النحوية التي تبحث فيها نائب الفاعل، و استنباط النتائج وأسباب حذف الفاعل في نائب الفاعل من الآيات القرآنية في القرآن

$$
\text { الكريم يعني في جزء } 30
$$

لمحة عن سورة الزلزلة

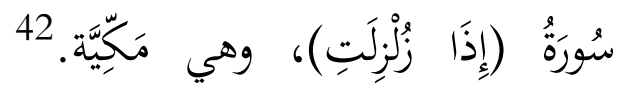
مدنية، وقيل: مكية، وآيها: ثماني آيات، وحروفها: مئة وخمسة وخمسون حرفًا، وكلمها: خمس وثلاثون كلمة. لمحة عن سورة العاديات سُورَةُ (وَالْعَادِيَاتِ)، مَكِكِيَّة. 44 مختلف لف فيها كالتي قبلها، وآيها: إحدى عشرة آية، وحروفها: مئة وتمانية وستون حرفًا، وكلمها: أربعون كلمة. 45 لمحة عن سورة التَّكَاثُرُ مكية، وآيها: ثماني آيات، وحروفها: مئة وتسعة عشر حرفًا، وكلمها: ثمان وعشرون كلمة. عاقبة التكاثر في المال والجاه. 46 لمحة عن سورة الممزة سُوْرَة المُمَزَة مكية، وآيها: تسع آيات، وحروفها: مئة وثلاثون حرفًا، وكلمها: ثناث وثلاثون كلمة. لمحة عن سورة الإخْلاص

$$
\begin{aligned}
& 46 \text { بجير الدين، فتح، } 600 \\
& \text { 47 } 4001 \text { الدير الدين، فتح، فئح، } 601 \\
& \text { 48 }
\end{aligned}
$$

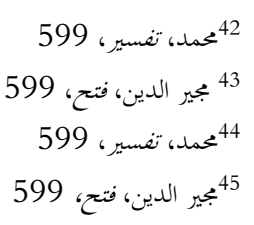


Al Bariq : Jurnal Pendidikan Bahasa Arab, 2, (2), 2021, 21-36

\begin{tabular}{|c|c|c|c|c|c|c|}
\hline \multirow[t]{2}{*}{ الإعراب } & \multirow{2}{*}{ أسباب } & \multicolumn{2}{|c|}{ نائب الفاعل } & \multirow{2}{*}{ الآية } & \multirow{2}{*}{ نمر } & \multirow[b]{2}{*}{ ق } \\
\hline & & رّم & ص ال & & & \\
\hline فل فلامة رفعه الضمارع مرفوع و & للعلم به & $\checkmark$ & & يُنْنَخُ & $\begin{array}{l}1 \\
8\end{array}$ & 1 \\
\hline علائب فاعل مرفوع و & للعلم به & & $\checkmark$ & السَّمَاءُ & 9 & 2 \\
\hline علائب فاعل مرفوع و الظاهرة. & للعلم به & & $\checkmark$ & المُجِكالُ & $\begin{array}{l}2 \\
0\end{array}$ & 3 \\
\hline
\end{tabular}

أ. سورة النازعات.

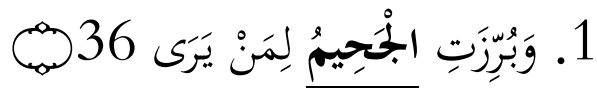

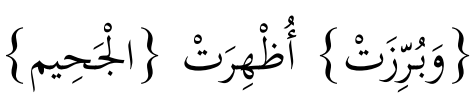

النَّار الْمُحْرِقِة \}ِلمَنْ يَرَى

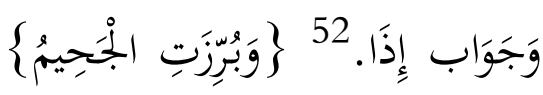

نتائج البحث ومناقشها

تحليل نائب الفاعل وأسباب حذف الفاعل

فيه في القرآن الكريم في جزء 30

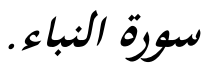

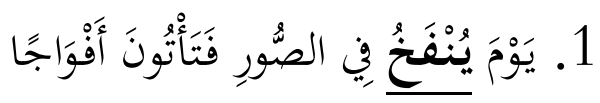

(i)

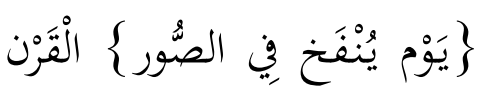

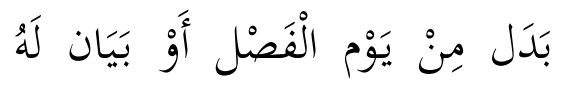

وَالنَّافِخ إِمْرَافيل.

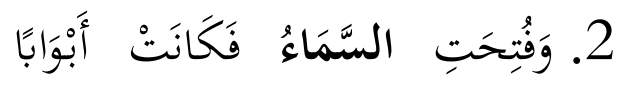

Q19

قرأ

الكوفيون: (وَفْتَتَتِ) بتخفيف

التاء. والباقون: بالتشديد (1)؛

أي: شُقَّت لنزول الملائكة

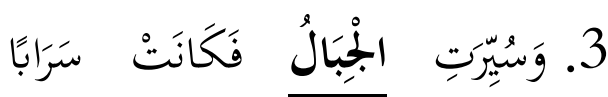

Q 20

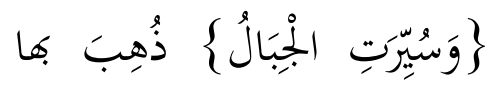

عن أماكنها

يُري كالسراب. 
Al Bariq : Jurnal Pendidikan Bahasa Arab, 2, (2), 2021, 21-36

د. سورة التكويو.

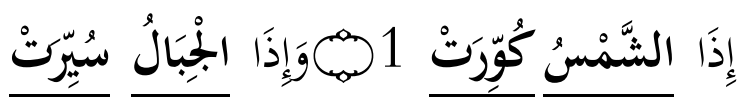

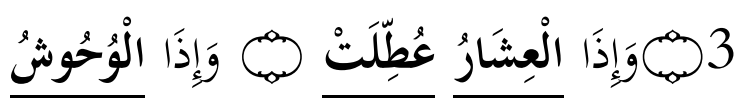

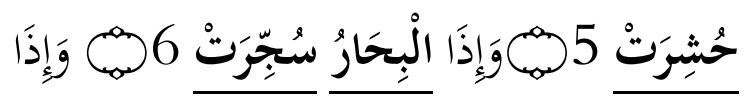

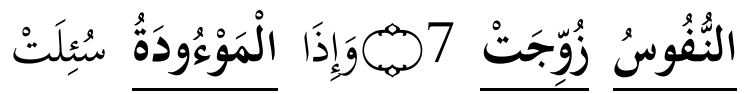

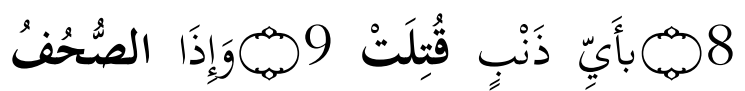

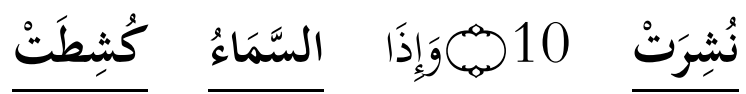
11 أُزْلِفَتْتْ 13

\begin{tabular}{|c|c|c|c|c|c|c|}
\hline \multirow[t]{2}{*}{ الإعراب } & \multirow{2}{*}{ حذف أسباب } & \multicolumn{2}{|c|}{ نائب الفاعل } & \multirow{2}{*}{ الآية } & \multirow[t]{2}{*}{ الآ } & \multirow{2}{*}{ ق } \\
\hline & & 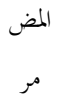 & ارح & & & \\
\hline مخذوف يفسره ما بعده. & للعلم به & & $\checkmark$ & الشَّْمْسُ & 1 & 1 \\
\hline 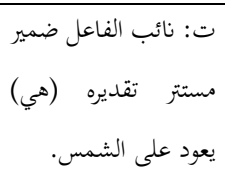 & للعلم به & $\checkmark$ & & كُوِرَتْتُ & 1 & 2 \\
\hline 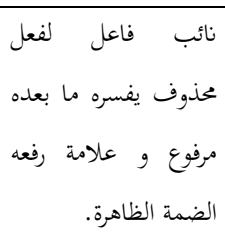 & للعلم به & & $\checkmark$ & الجْبَبالُ & 3 & 3 \\
\hline تمستر : نقائب الفاعل ضمير & للعلم به & $\checkmark$ & & سمُِِِتَتْ & 3 & 4 \\
\hline محذوف يفسره مائب البعده & للعلم به & & $\checkmark$ & الْعِشَارُ & 4 & 5 \\
\hline
\end{tabular}

أُظهرت $\}$

دخوهُما. 53

\begin{tabular}{|c|c|c|c|c|c|c|}
\hline \multirow[t]{2}{*}{ الإعراب } & حذف أسباب & \multicolumn{2}{|c|}{ نائب } & الآية & نم & ق \\
\hline & الفاعل & م' & ص ال & & ية & r \\
\hline عائب فاعل مرففع و & للعلم به & & $\checkmark$ & 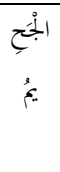 & 6 & 1 \\
\hline
\end{tabular}

ج. سورة عبس.

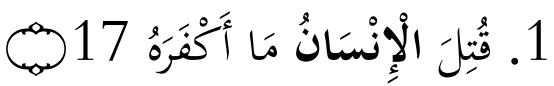
قُقتِلَ الْإِنْسَانُ \{ُعن ع بنعم الََكْفَهُهُ إحسانه إليه على طريق التعجب، نزلت في عتبة بن أبي لهب. 54

\begin{tabular}{|c|c|c|c|c|c|c|}
\hline \multirow[t]{2}{*}{ الإعراب } & حذف & \multicolumn{2}{|c|}{ الفائب } & نص الآية & ية & J \\
\hline & الفاعل & مر & ص ص ال & & & r \\
\hline الظائب فاعل مرفوع و & للإغبة في & & $\checkmark$ & الْإِنْسَ & $\begin{array}{l}1 \\
7\end{array}$ & 1 \\
\hline
\end{tabular}


Al Bariq : Jurnal Pendidikan Bahasa Arab, 2, (2), 2021, 21-36

\begin{tabular}{|c|c|c|c|c|c|c|}
\hline تمستر ن نقائب الفاعل ضمير & للجهل به & $\checkmark$ & & قُتْلَكتْ & 9 & $\begin{array}{l}1 \\
5\end{array}$ \\
\hline 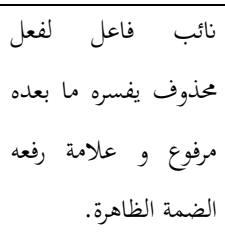 & للعلم به & & $\checkmark$ & فُصُّحُ & $\begin{array}{l}1 \\
0\end{array}$ & $\begin{array}{l}1 \\
6\end{array}$ \\
\hline تمستر نقائب الفاعل ضمير & للعلم به & $\checkmark$ & & نُشَرَتْْ & $\begin{array}{l}1 \\
0\end{array}$ & $\begin{array}{l}1 \\
7\end{array}$ \\
\hline 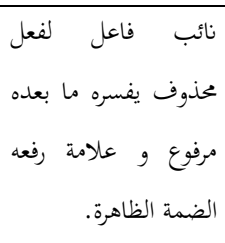 & للعلم به & & $\checkmark$ & السَّمَاءُ & $\begin{array}{l}1 \\
1\end{array}$ & $\begin{array}{l}1 \\
8\end{array}$ \\
\hline تمستر ت نقائب الفاعل ضمير & للعلم به & $\checkmark$ & & 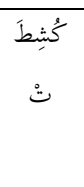 & $\begin{array}{l}1 \\
1\end{array}$ & $\begin{array}{l}1 \\
9\end{array}$ \\
\hline 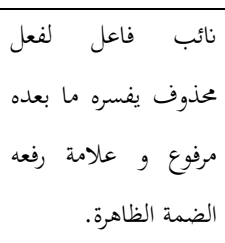 & للعلم به & & $\checkmark$ & الجُجِحيمُ & $\begin{array}{l}1 \\
2\end{array}$ & $\begin{array}{l}2 \\
0\end{array}$ \\
\hline 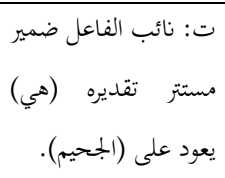 & للعلم به & $\checkmark$ & & سُعِرَتْتُ & 2 & $\begin{array}{l}2 \\
1\end{array}$ \\
\hline 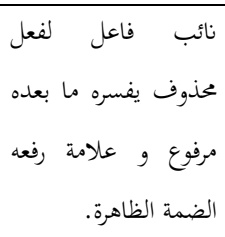 & للعلم به & & $\checkmark$ & الجنَّنَُّ & $\begin{array}{l}1 \\
3\end{array}$ & $\begin{array}{l}2 \\
2\end{array}$ \\
\hline تمستر ائب الفاعل ضمير & للعلم به & $\checkmark$ & & أَُْْلِفَتْتْ & 3 & $\begin{array}{l}2 \\
3\end{array}$ \\
\hline
\end{tabular}

\begin{tabular}{|c|c|c|c|c|c|c|}
\hline الضمة الظاهرة. و علامة رفعه & & & & & & \\
\hline 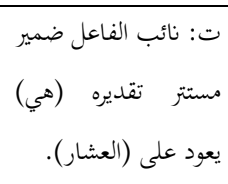 & للعلم به & $\checkmark$ & & عُطِطَتَتْ & 4 & 6 \\
\hline 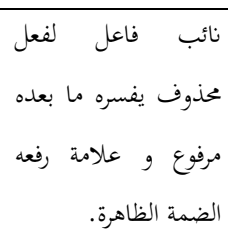 & للعلم به & & $\checkmark$ & الْوُحُوشُشُ & 5 & 7 \\
\hline 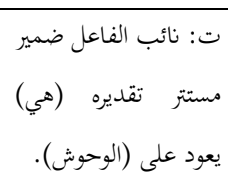 & للعلم به & $\checkmark$ & & حُشِرَتَتْ & 5 & 8 \\
\hline 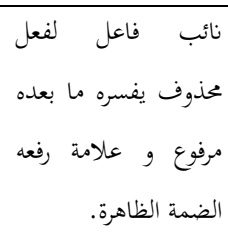 & للعلم به & & $\checkmark$ & الْبِحَارُ & 6 & 9 \\
\hline 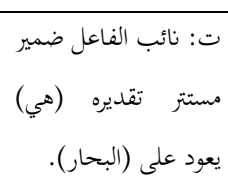 & للعلم به & $\checkmark$ & & 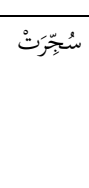 & 6 & $\begin{array}{l}1 \\
0\end{array}$ \\
\hline 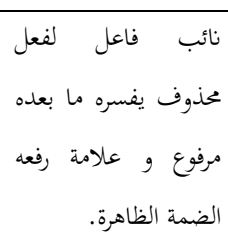 & للعلم به & & $\checkmark$ & النُُُوُسُ & 7 & $\begin{array}{l}1 \\
1\end{array}$ \\
\hline تمت: نائب الفاعل ضمير & للعلم به & $\checkmark$ & & زُوََْجَتْ & 7 & \\
\hline 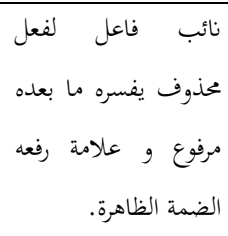 & للعلم به & & $\checkmark$ & 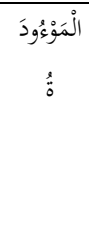 & 8 & 1 \\
\hline 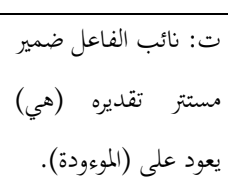 & للعلم به & $\checkmark$ & & سُسِلَتَتْ & 8 & 1 \\
\hline
\end{tabular}




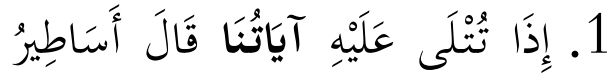

$$
\text { الْأَوَلِينَ } 13
$$

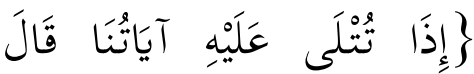

أَسَاطِيرُ الْأَوَّلِينَ

وهي الحكايات التي سُطِرتَ

$$
\text { قديمًا. }
$$

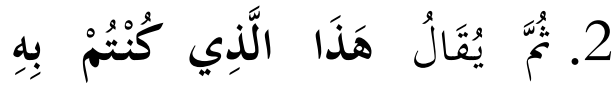

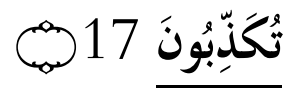

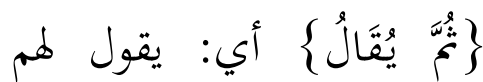

الزبانية توبيخًا: رهذَأ العذاب.

58 . 58

3. يُسْقَوْنَ مِنْ رَحِيقِ عَتْوِرٍ 25

يُسْقَوْنَ مِنْ رَحِيقِ

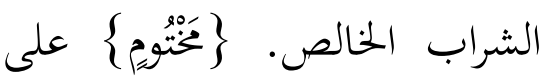

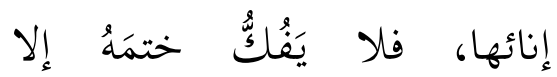

$$
\text { الأبرارُ . }
$$

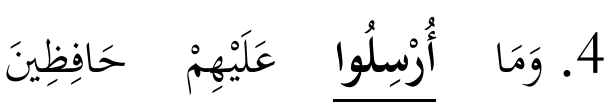

$$
\text { (.) } 33
$$

\section{1. وَإِذَا الْبْحَارُ فُجِّرَتْ 3.}

فُ فَإِذَا الْبِحَارُ فُجِّرَتْ

بعضُها إلى بعض، عذَجُا وِِلْحُها،

فصارت بحرًا واحلًا. 55

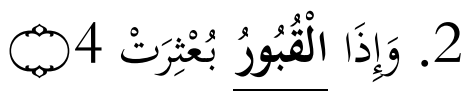

وَ

$$
\begin{aligned}
& \text { وأُخرج ما فيها من الموتى، وهذه } \\
& \text { أوصاف يوم القيامة. } 56
\end{aligned}
$$

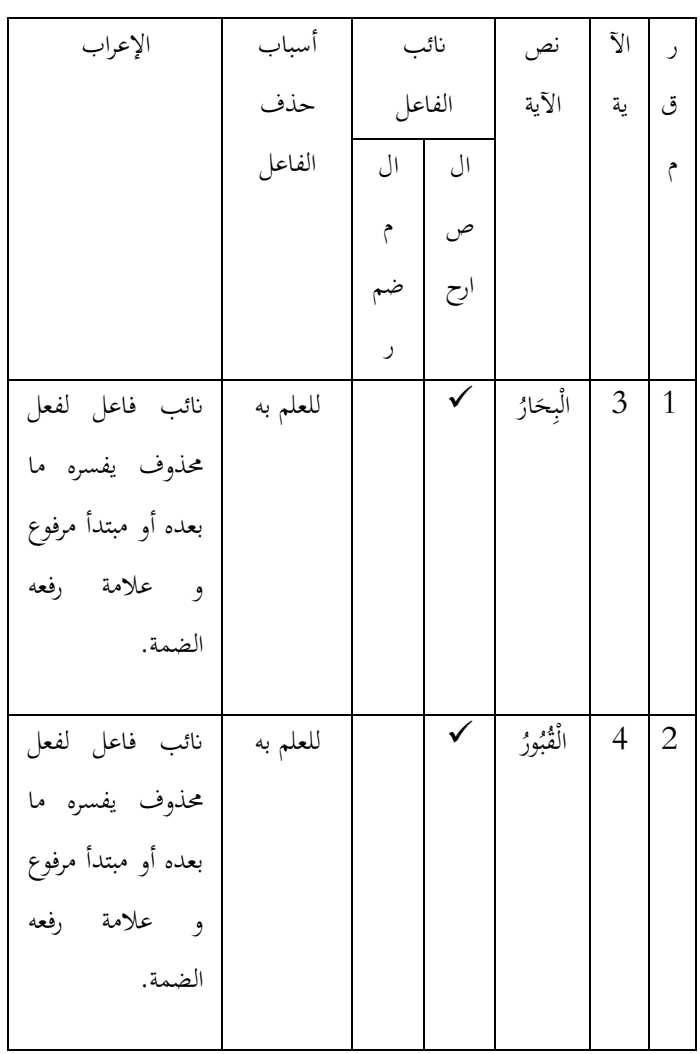


Al Bariq : Jurnal Pendidikan Bahasa Arab, 2, (2), 2021, 21-36

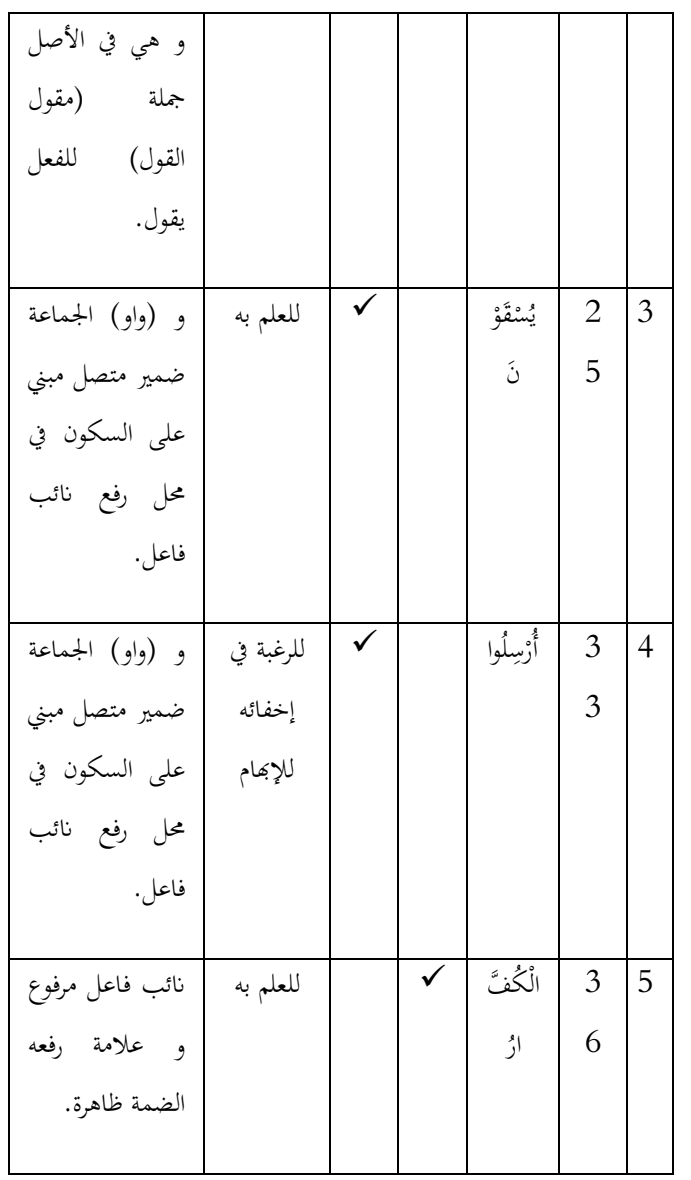

㑭

على $\quad$ على $\quad$ المؤمنين

لمافِظِينَ

60

مصالحهم.

5. هَلْ ثُوِبَ الْكُفَّارُ مَا كَانُوا يَفْعَلُونَ

36

قال تعالى: $\}$

جوزي $\}$

أي: جزاءَ استهزائهم بالمؤمنين،

والاستفهام تقرير وتوقيف لمحمد -

صلى الله عليه وسلم - وأمته. و الله

الحنالاصة

وجد نائب الفاعل في جزء 30 ثلاث

و ستّين كلمة من أربع أنواع. يعني: نائب

الفاعل الصارح (27): في السورة النباء (2)،

في السورة النازعات (1)، في السورة عبس (1)،

في السورة التكوير (11)، في السورة الانفطار

(2)، في السورة المطففين (2)، في السورة

الانشقاق (1)، في السورة البروج (1)، في 
وتكون للرغبة في إخفائه للإبهام (9):

في السورة عبس (1)، في السورة المطففين (2)،

في السورة الانشقاق (1)، في السورة البروج (1)، في السورة الغاشية (1)، في السورة الفجر (1)، في السورة البينة (1)، في السورة الهمزة (1). وللجهل به (1): في السورة التكوير (1).

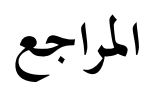

محمّد علي الصابوني، التبيان في علوم القرآن (ط. جديدة؛ باكستان : مكتبة

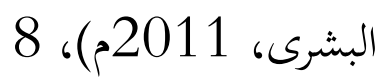

M. Asy'ari, Metodologi Pendidikan dan Pengajaran Perspektif Al-Qur'an dan Hadits (Tangerang : Rabbani Press, 2017), 3

$$
\text { القرآن، } 12 \text { (يوسف) } 2 .
$$

تيتن فاطمة و إرفان. "الاسم الني لا لينصرف لأل وطرق تدريسه في مدرسة الخيرات

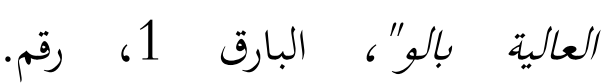

$$
25: 2020) 1
$$

مصطفى الغلايين، جامع الدروس العربية (لبنان: دار الفكر، 2007)، 7

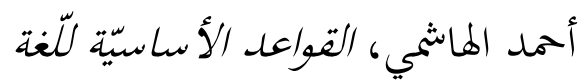
العربيّة (لبنان: دار الكتب

$$
\text { العلمية، 2009)، } 6
$$

السورة الطارق (1)، في السورة الفجر (3)، في السورة الليل (1)، في السورة الزلزلة (1). نائب الفاعل المضمر(33): في السورة النباء (1)، في السورة التكوير (12)، في السورة المطففين (2)، في السورة الانشقاق (6)، في السورة الطارق (1)، في السورة الغاشية (5)، في السورة البينة (2)، في السورة الزلزلة (1)، في السورة التكاثر (1)، في السورة الهمزة (1)، في السورة الإخلاص (1).ونائب الفاعل الجملة (1): في السورة المطففين (1). نائب الفاعل اسم الموصول(2): في السورة العاديات (2). وجدت أسباب حذف الفاعل في نائب الفاعل في جزء 30 كما يلي: للعلم به (53): في السورة النباء (3)، في السورة النازعات (1)، في السورة التكوير (22)، في السورة الانفطار (2)، في السورة المطففين (3)، في السورة الانشقاق (6)، في السورة الطارق (2)، في السورة الغاشية (4)، في السورة الفجر (2)، في السورة الليل (1)، في السورة البينة (1)، في السورة الزلزلة (2)، في السورة العاديات (2)، في السورة التكاثر (1)، في السورة الإخلاص 
وهبة بن مصطفى الزحيلي، التغسير الوسيط للزحيلي (دمشق : دار الفكر، 142

هـ)، 582
فؤاد نعمة، ملخص قواعد اللغة العببية (الجزء: الأول، بيروت: دار الثقافة

$$
\text { الإسلامية، دون سنة)، } 17
$$

عبد الله ابن الفاضل الشيخ العشماوي، شرح حاشية لعشموي (سورابايا: الهداية،

$$
\text { دون سنة)، } 25
$$

محمد بن محمد الرعيني، متممة الأجرومية الطبعة الرابعة الجزء الأول (بيروت-لبنان:

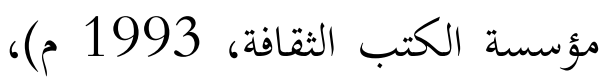
267

أحمد طيب رايا و واتي سوسييا واتي، المختصر في النحو (جاكرتا : الجامعة شريف هداية الله الإسلامية الحكومية، 83 2016

أحمد طيب رايا و واتي سوسييا واتي، المختصر، 88-86

محمد بن محمد بن محمود، أبو منصور الماتريدي، تفسير الماتريلدي (تأويلات أهل السنة) (لبنان : دار الكتب العلمية، 582 2005

مجير الدين، فتح الرحمن في تغسير القرآن (إدَارَةُ الشُؤُونِ الإِسلاَمِيّة : إصدَّارات وزَّارة

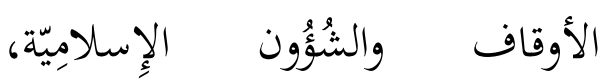
582 2009 